\title{
A emergência da Sociologia da Infância: rupturas conceituais no campo da Sociologia e os paradoxos da Infância na contemporaneidade
}

\section{The emergence of the Sociology of Childhood: conceptual ruptures in the field of Sociology and paradoxes of childhood in contemporary society}

\author{
Sabrina da Costa Dias é graduada em Pedagogia pela \\ Universidade de São Paulo (USP) e mestranda em Sociologia da \\ Infância pela mesma universidade. Atualmente é professora de \\ educação infantil na rede privada de ensino.
}

Contato: sabrinadias1@gmail.com

\section{Resumo}

Há pouco mais de uma década a sociologia tem mostrado maior interesse em estudar a infância, as crianças e suas relações com os demais grupos sociais. Em grande parte, este interesse não está isolado da sociedade em geral, visto que nos últimos anos temos assistido à emergência de um grande debate sobre as crianças e a infância, demonstrado pelas inúmeras discussões a seu respeito na mídia, assim como nas diversas ciências que passaram a contextualizála. Tomando como pressuposto que o fenômeno social da infância é influenciado pelas forças macroestruturais, o presente artigo tem como objetivo mostrar as mudanças conceituais no campo da Sociologia que possibilitaram a emergência da Sociologia da Infância, contribuindo para a sua difusão, além de mostrar que o interesse geral pelas crianças também oculta determinados paradoxos relacionados à infância, sobretudo no contexto das transformações sociais na contemporaneidade. Palavras Chave: sociologia; infância; modernidade; infância contemporânea. 


\begin{abstract}
Just over a decade sociology has shown greater interest in studying children and their relations with other social groups. In large part, this interest is not isolated from society in general, since in recent years have witnessed the emergence of a great debate about children, shown by the numerous discussions about it in the media as well as the various sciences that began to contextualize it. Taking for granted that the social phenomenon of childhood is influenced by macro-forces, this article aims to show the conceptual changes in the field of sociology that allowed the emergence of the sociology of childhood, contributing to its spread, and show that the interest in general about the children also hides certain paradoxes related to childhood, especially in the context of social changes in contemporary society.

Keywords: sociology; childhood; modernity; contemporary childhood.
\end{abstract}

\title{
O desenvolvimento da Sociologia da Infância
}

0 crescente debate a respeito das questões da infância pode ser cotidianamente encontrado em revistas, jornais, televisão, internet, livros, entre outros. Porém, o fato é que as pesquisas orientadas sobre a infância quase sempre a analisaram como parte constituinte de outros objetos de estudo, em grande parte, da família. Ou seja, as crianças e a infância não eram dotadas de autonomia conceitual e não eram compreendidas como categorias de estudo. Tal situação levou os sociólogos franceses a definirem a infância como fantasma onipresente ou terra incógnita, já os sociólogos britânicos a chamaram de marginalizada, excluída, invisível, conforme afirma Sirota (2001). Independente do termo utilizado, todos procuram expressar a condição de exclusão da infância das análises sociológicas até então.

Porém, em meados da década de 1980, um novo campo de estudos surgiu no interior da sociologia e passou a ser denominado de Sociologia da Infância. A emergência desse novo campo esteve, em grande parte, relacionada ao rompimento com as clássicas teorias da socialização, não somente ao que se refere ao conceito de socialização, como também no que se refere às concepções de sociedade e de sujeito social. 
Nesse sentido, é essencial retornarmos à corrente denominada Sociologia Clássica a fim de compreender não somente a emergência e delimitação do campo da Sociologia da Infância bem como as transformações sociais que afetam o entendimento e as relações com esse grupo geracional.

Conforme aponta Fernandes (1960, p. 29), o excessivo recorte disciplinar da sociologia parece impróprio por não corresponder aos processos sociais reais. Nesse sentido, aqueles que trabalham em favor das novas "sociologias especiais" devem tentar ao máximo compreender o movimento da sociologia geral, de modo que a divisão disciplinar não termine por fragmentar excessivamente o conhecimento construído.

Por isso, antes mesmo de adentrarmos nas discussões trazidas pela Sociologia da Infância, bem como compreendermos o movimento que levou à sua emergência, cabe questionarmos "o que é a Sociologia?". Ainda que diferentes autores a tenham definido, preferencialmente trabalharemos neste artigo com a afirmação de Florestan Fernandes: "a sociologia é a ciência que estuda os fenômenos sociais" (1960, p. 19). Convém explicitar que por fenômenos sociais compreendemos "as atividades ou comportamentos cuja manifestação, generalidade e repetição dependem, direta ou indiretamente, das formas de agregação e de associação entre os organismos" (idem). Faz-se necessário neste momento frisar a diferença entre as ciências naturais e ciências sociais devido a fato de a primeira ter como objeto de estudo o organismo biológico, enquanto que a segunda procura identificar os fenômenos que possuem regularidade na vida social.

Ora, durante um longo período, a infância foi concebida como fase biológica e universal da vida humana, sendo, portanto, objeto de estudo das ciências naturais. Porém, a partir do momento que os sociólogos passaram a questionar tal concepção e argumentar que a infância constitui um fenômeno social por representar uma forma institucionalizada de vida social e por apresentar regularidade em sua presença na sociedade, é que a infância deixou de ser objeto de estudo das ciências naturais e passou a ser conceitualizada pelas ciências sociais. 
A concepção de infância enquanto fase biológica se refere ao discurso que compreende a infância como um período de transição no qual a criança está em processo de desenvolvimento e o objetivo final desse período consiste em atingir a maturidade na idade adulta. Essa concepção de infância esteve fortemente presente na sociologia clássica e atrelada aos conceitos de socialização. Tal afirmação pode ser observada no entendimento de socialização cunhado por Durkheim:

\section{[...] a sociedade se encontra, a cada nova geração, como que diante de uma tábula rasa, sobre a qual é preciso construir quase tudo de novo. É preciso que, pelos meios mais rápidos, ele agregue ao ser egoísta e associal, que acaba de nascer, uma natureza capaz de vida moral e social, eis aí a obra da educação. Ela cria no homem um ser novo (Durkheim, 1978, p. 42).}

Nesse sentido, observa-se que a ênfase da análise sociológica esteve presente nos métodos e instituições socializadoras, cujo objetivo principal era a idade adulta. Conforme afirma Sirota (2001), a sociologia em geral, e principalmente a sociologia da educação, esteve durante muito tempo restrita à concepção durkheimiana, daí a marginalização conceitual da infância nesse campo do conhecimento.

Porém, é importante verificar também que a concepção de criança estava atrelada às concepções de sujeito social e de sociedade que em muito diferem das concepções contemporâneas. As concepções formuladas por Durkheim provêm de um tempo histórico no qual a sociedade era fundamentada pela tradição e pelo costume, representava um sistema homogêneo e unificado de valores e papéis sociais. "A sociedade era interpretada como uma totalidade, um conjunto coerente e organizado no qual o ator era o sistema" (Wautier, 2003, p. 76). Nesse sentido, ao sujeito social restava apenas seguir os caminhos impostos pela coerção social, na medida em que o sujeito social em Durkheim nada mais era que um reprodutor da ordem estabelecida, de forma que o sucesso da socialização era interpretado como uma total identificação do sujeito com os valores societários (Setton, 2005, p. 52).

Portanto, a ideia de criança como vir a ser e ser associal estava atrelada às concepções de sociedade, sendo que, dado o poder definidor da tradição e do costume, a consciência coletiva moldava a consciência individual, restringindo o papel do ator social, o qual era concebido como sujeito devido à sua pouca atividade. Nesse contexto, a criança era compreendida como um ser que deveria ser controlado e domesticado pelos processos de socialização.

Porém, conforme aponta Giddens (2000), o movimento 
histórico conhecido como lluminismo viria a questionar a tradição e o costume como ligados ao obscurantismo e à ignorância. Tais ideias levaram à ruptura com a tradição, trazendo, assim, severas modificações para a vida social, sobretudo para a construção da identidade pessoal. Onde a tradição recuou, abriu-se espaço para a escolha individual.

As mudanças desencadeadas pela desagregação da tradição e do costume, assim como a emergência de uma nova agência socializadora, a mídia, e a construção de novas relações entre espaço e tempo (Giddens, 1994) modificaram as sociedades estruturalmente. Logo, as teorias clássicas da socialização passaram a não mais explicar o processo de socialização na contemporaneidade. Conforme afirma Dubet (1998), as instituições que atribuíam significado e coerência ao processo de socialização do indivíduo, como a família, a religião e a escola foram perdendo sua força socializadora.

Dessa maneira, novas formas de pensar a sociedade foram sendo articuladas. Para Giddens (1994), a modernidade, sem as certezas da tradição e do hábito, e a pluralidade de escolhas tornada possível garantiram ao sujeito social a capacidade de deliberar sobre sua própria trajetória:

\footnotetext{
Porém, e por causa da "abertura" da vida social de hoje, da pluralidade de contextos de ação e da diversidade de "autoridades", a escolha de um estilo de vida tem uma importância crescente na constituição da autoidentidade e da atividade quotidiana (Giddens, 1994, p. 4 - grifos do autor).
}

Segundo Giddens (1994), a partir do momento que a vida individual deixou de ser guiada pela tradição, a possibilidade de escolha entre estilos de vida abriu espaço para múltiplas formas de sociabilidade. Nesse sentido, a ideia de sociedade como sistema único e integrado de valores foi deixada para trás e a concepção de sociedade enquanto esfera permeada por instituições e valores que podem até ser contraditórias entre si ocupou seu lugar. Ou seja, se escola e família eram, para a sociologia clássica as principais instituições encarregadas pela socialização, na contemporaneidade elas concorrem com outras agências socializadoras.

O surgimento de um universo cultural plural e diversificado na contemporaneidade rompeu com a interpretação da sociedade enquanto sistema único e integrado de valores. Logo, a linearidade e a complementaridade entre os princípios e papéis interiorizados em diferentes contextos sociais não estariam garantidas. Diante de contextos sociais diversificados e experiências múltiplas, ao 
indivíduo é atribuída a possibilidade de escolha. Ao indivíduo é dada a responsabilidade por seu próprio processo de socialização, na medida em que necessita significar suas experiências. Se a teoria clássica da Sociologia compreende o processo de socialização enquanto sinônimo de interiorização dos valores, crenças e papéis sociais, Dubet (1996), verificando a existência de contextos de ação diversificados na modernidade, aponta que o indivíduo já não é mais capaz de interiorizar papéis, mas apenas de fundar experiências, cabendo-lhe significar as diferentes experiências sofridas. Dessa maneira, ele deixa de ser mero objeto de socialização para se tornar aǵente.

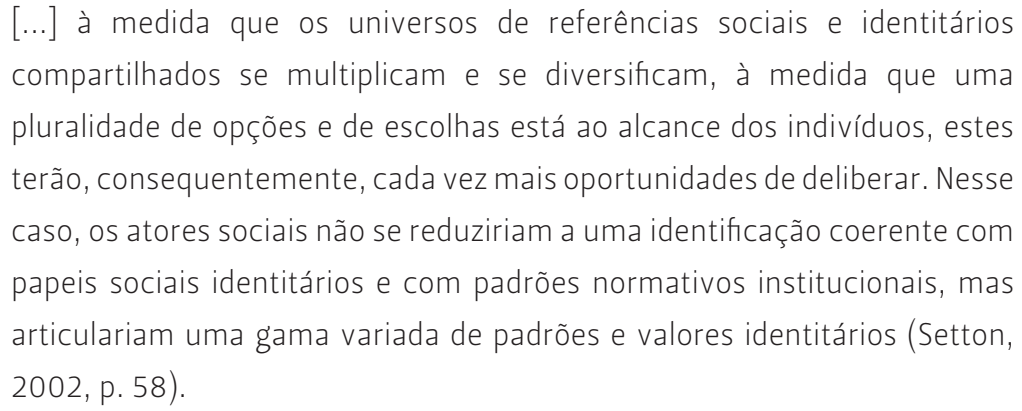

Dubet (1996) compreende que a esfera social possui diferentes lógicas de ação, ou seja, diferentes universos simbólicos, crenças e valores e que desde muito cedo, temos contato com tais lógicas de ação. Nesse sentido, não somos mais capazes de interiorizar papéis, subjetivando-os completamente, nem de formarmos uma identidade única (Lahire, 2000), mas apenas de fundar experiências.

As transformações estruturais e rupturas com paradigmas da Sociologia Clássica tornaram-se ponto de partida para a emergência da Sociologia da Infância na medida em que ela se confronta com a concepção de criança enquanto objeto de socialização (Sirota, 2001), afirmando a ideia de criança ativa, competente e sujeito de direitos além de debruçar-se sobre a particularidade do processo de socialização na contemporaneidade. Nota-se que ao ator é atribuída maior autonomia e responsabilidade por seu próprio processo socializador. Corsaro (2011), importante sociólogo norte-americano, porém, critica o uso do termo socialização, pois este termo carrega a pré-concepção de uma etapa de preparação para a vida adulta. Propõe, então, o termo Reprodução Interpretativa, por defender que: 
Corsaro (2011) compreende o papel ativo da criança em oposição às teorias da sociologia clássica, negando o fato de as crianças apenas internalizarem e reproduzirem o mundo adulto. $\mathrm{Na}$ verdade, o referido autor compreende que as crianças se esforçam para interpretar e atribuir sentido ao mundo adulto, produzindo coletivamente seus próprios mundos. Corsaro (2002) fundamenta seus estudos na análise das culturas infantis, argumentando que as atividades e significados partilhados contribuem para a sociedade em geral. Porém, essa contribuição somente é possível porque as crianças, enquanto coletivo, participam não somente de sua cultura como também da cultura adulta. Ou seja, é a partir da interação com diferentes lógicas de ação em idade precoce que as crianças iniciam o compartilhamento com várias culturas de pares.

Dessa maneira, repensando as teorias da socialização, percebemos que a criança passou de um lugar passivo para um lugar ativo; de um grupo silenciado para um grupo presente e contribuinte da sociedade em geral. E o fato de a infância ser contextualizada pelas ciências sociais, deixando de ser compreendida como fase universal e biológica da vida humana, desencadeou uma série de rupturas paradigmáticas no interior da Sociologia.

\footnotetext{
0 afastamento em relação à posição durkheimiana é claro. Trata-se de romper a cegueira das ciências sociais para acabar com o paradoxo da ausência das crianças na análise científica da dinâmica social com relação ao seu ressurgimento nas práticas consumidoras e seu imaginário social (Sirota, 2001, p. 11).
}

\section{Estudos estruturais da infância}

Embora não seja tão fácil compreender, conforme afirma Sarmento (2009), a Sociologia da Infância não se preocupa unicamente com as crianças, pelo contrário, este novo campo da Sociologia busca compreender a sociedade a partir de um novo objeto de estudo: o fenômeno social da infância.

\footnotetext{
É por isso que, na verdade, ao estudar a infância, não é apenas com as crianças que a disciplina se ocupa: é, com efeito, a totalidade da realidade social o que ocupa a Sociologia da Infância. Que as crianças constituem uma porta de entrada fundamental para a compreensão dessa realidade é o que é, porventura, novo e inesperado no desenvolvimento recente da disciplina (Sarmento, 2009, p. 19. grifos do autor).
} 
A Sociologia da Infância propõe uma diferenciação analítica do seu objeto de estudo: as crianças são, portanto, atores sociais, enquanto que a infância é compreendida como categoria social de tipo geracional.

A Sociologia da Infância, assim como as demais ciências componentes das ciências sociais, não está livre de diferenças internas em seu próprio campo. Conforme aponta Sarmento (2009), as ciências sociais não são um campo no qual facilmente são produzidos consensos, pelo contrário, as diferenças no interior do campo são decorrentes de discordâncias conceituais, métodos ou problemáticas analisadas, afiliação a determinadas escolas de pensamento, entre outros, originando diferentes correntes dentro do mesmo campo.

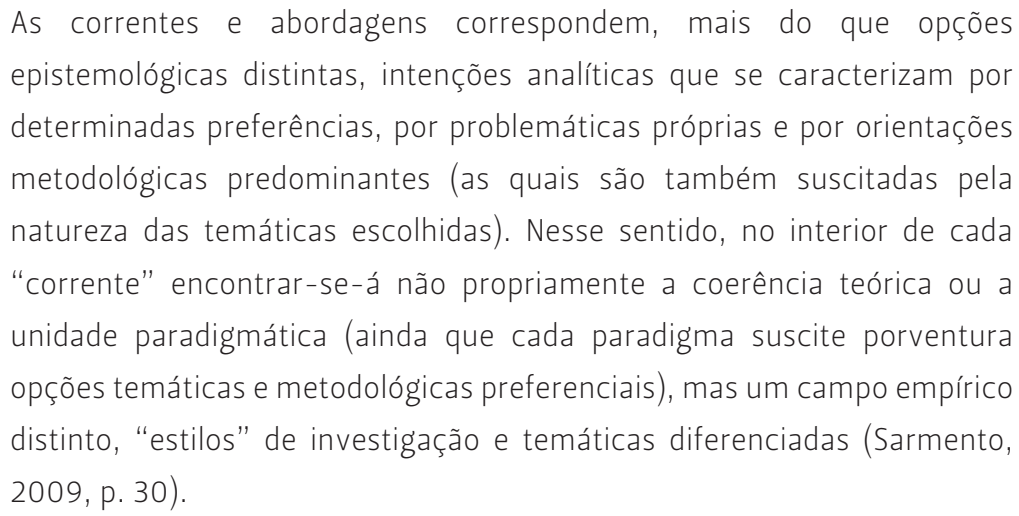

Desse modo, os estudos do campo são segmentados em três abordagens principais: estudos estruturais, estudos interpretativos e estudos de intervenção. Por compreender que os estudos estruturais trazem maiores contribuições referentes aos objetivos do presente artigo, a seguir, trabalharemos apenas com essa abordagem.

A perspectiva dos estudos estruturais tem como um de seus principais autores o sociólogo dinamarquês Jens Qvortrup que define a infância como categoria social permanente na estrutura social. 0 entendimento da infância enquanto categoria presente e permanente na estrutura social afirma que as crianças, enquanto grupo, possuem uma identidade comum, ou seja, a infância constitui uma forma estrutural particular, definida não pelas características individuais das crianças, mas por suas demandas comuns. A partir da concepção de infância enquanto forma estrutural, é possível compará-la a outras formas de estratificação social. Portanto, a afirmação da infância enquanto categoria estrutural permite identificar as características comuns às crianças 
e então evitar confundir suas condições de vida com as condições de vida de seus pais (Qvortrup, 1993, p. 5). Dessa maneira,

\begin{abstract}
Não podemos, a partir de uma análise de classes, tirar quaisquer conclusões sobre crianças como categoria. Isso não é negar as diferenças entre as crianças, mas demonstrar os limites do emprego de um foco aqui, classe que antes divide as crianças do que as reúne sob um denominador comum. (Qvortrup, 2010a, p. 1127).
\end{abstract}

A infância enquanto categoria permanente reside na ideia de que ainda que as crianças cresçam e deixem a infância, outros passarão a integrá-la: "o desenvolvimento histórico da infância não acaba com sua categoria, e a variabilidade cultural da infância contemporânea testemunha a favor de sua presença universal" (Qvortrup, 2010b, p. 637).

Portanto, verifica-se a notável contradição entre a concepção de infância enquanto tábula rasa, defendida por Durkheim, e a concepção de categoria permanente, argumentada por Qvortrup. Enquanto que a primeira compreendia que as crianças constituíam seres associais e que, portanto, viriam fazer parte da sociedade na idade adulta, a segunda afirma que a infância já é parte integrante da sociedade e que seus integrantes, as crianças, são seres ativos cuja contribuição para a sociedade se dá pela interação contínua com os demais grupos da estrutura social.

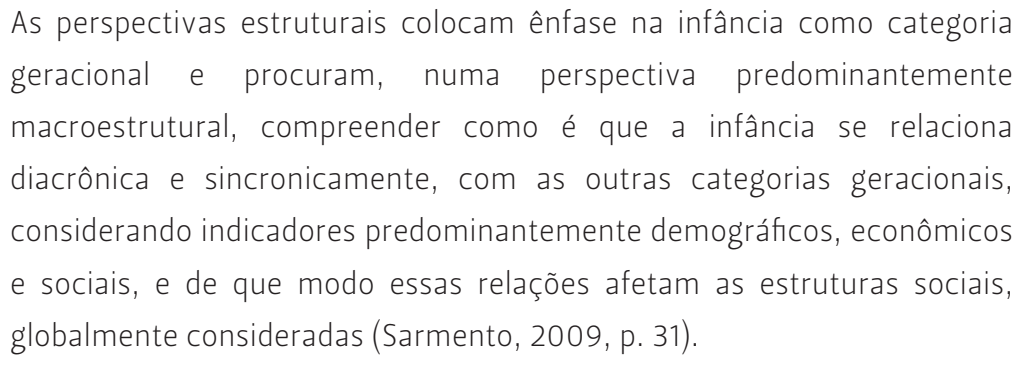

A perspectiva estrutural da infância permite observarmos que, do mesmo modo que os demais grupos da estrutura social, a infância é influenciada por parâmetros e forças externas que, de alguma maneira, impactam sua definição e as relações mantidas com ela. Ao reconhecer que a infância não possui representações universais e que o modo de defini-la perpassa um complexo processo sócio-histórico no qual se podem observar diferentes imagens e discursos construídos ao longo do tempo, compreendemos como tarefa da Sociologia da Infância identificar as concepções de criança e de infância atreladas aos contextos sociais, interrogando sobre quais eventos sociais, em um determinado período, impactaram a infância no que se refere a suas condições e modos de vida. 


\section{A Modernidade e os paradoxos da infância}

Um dos principais questionamentos trazidos pela abordagem estrutural da infância refere-se ao lugar reservado à criança na contemporaneidade, o que significa questionar como as mudanças trazidas pela modernidade afetaram a infância enquanto grupo geracional: os seus modos de socialização, suas condições de vida, bem como a relação entre ela e os demais grupos geracionais.

Conforme exploramos na primeira parte deste artigo, a sociologia contemporânea, tendo como autores de referência Giddens, Dubet, Lahire, entre outros, compreende a sociedade como uma nova ordem, não mais definida pela homogeneização de valores, mas marcada por um universo cultural heterogêneo e diversificado e pelo surgimento de novas agências socializadoras, as quais passaram a disputar o monopólio do processo de socialização com as instâncias reconhecidas como detentoras de tal monopólio: a escola e a família. Dadas as mudanças sociais observadas, tais autores passaram a utilizar os termos conceituais "sociedade tradicional" e "sociedade moderna" a fim de distinguir não somente o período histórico no qual situam seus estudos, mas para marcar as descontinuidades e transformações observadas nas sociedades após a década de 1970.

\footnotetext{
De qualquer modo, parece haver consenso entre os diversos autores que tratam o tema, de que desde os anos 70, mudanças e transformações muito profundas vêm ocorrendo nas práticas culturais, sócio-políticas e econômicas e que essas mudanças estão diretamente ligadas à emergência de novas maneiras dominantes de experimentarmos o tempo e o espaço (Marchi, 2005, p. 5).
}

Tal consenso, porém, não é observado no que se refere à passagem das sociedades modernas industriais para sociedades pós-modernas: enquanto que para Baumann (2001) a sociedade moderna mantém seu caráter de modernidade, mostrando apenas o outro vértice dela mesma, Giddens (1991) aponta que atualmente vivemos as consequências da modernidade em sua fase tardia.

No entanto, o que ambos os autores têm em comum referese ao fato de as mudanças estruturais ocorrerem devido a modificações na relação tempo e espaço, modificações essas que somente foram possíveis dada a ruptura com a tradição: "a modernidade é uma ordem pós-tradicional, mas sem que as certezas da tradição e do hábito tenham sido substituídas pela certeza do conhecimento racional" (Giddens, 1994, p. 2). 
A desagregação da tradição instituiu o principio da dúvida radical (Giddens, 1994), além de possibilitar a crise das instâncias de legitimação, ou seja, em meio à diversidade do universo cultural, perdemos nossas referências, pois não possuímos mais o peso da tradição que lhes conferiam o caráter de autoridade. Além disso, a reorganização do tempo e do espaço permitiu certa descontextualização das experiências vividas, instituindo uma nova relação entre o local e o global, de maneira que passamos a percorrer distâncias em cada vez menos tempo e de possuirmos contato com formas de vida em lugares distintos, tornando nossas experiências de vida cada vez menos presentes em um espaço de referência.

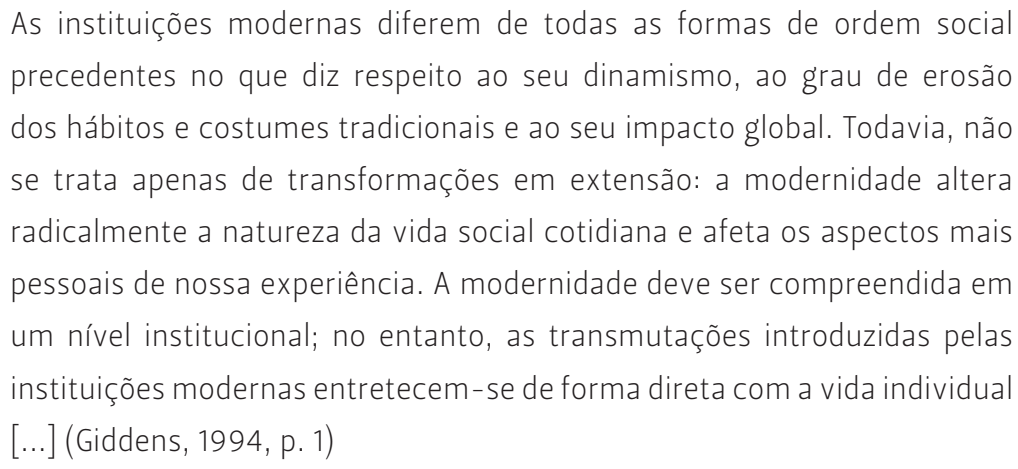

Se as transformações trazidas pela modernidade afetam diretamente as formas de vida, conforme apontou Giddens (1994), e aproximando suas contribuições aos estudos realizados por Qvortrup (2010b), nos quais afirma que as crianças são atingidas pelas forças macroestruturais, cabe-nos questionar quais são as consequências trazidas para a infância enquanto grupo geracional.

Um dos processos relativos à infância que podem ser considerados como consequência de forças macroestruturais refere-se ao chamado processo de Institucionalização da Infância (Sarmento, 2007). 0 termo utilizado tem como intuito sintetizar o processo de criação de diferentes instituições destinadas às crianças, sendo a primeira delas, a escola.

A institucionalização da infância teve inicio, portanto, na modernidade, com a criação das escolas e expansão das redes de ensino. A criança, ao adentrar os muros escolares, passava a desempenhar um novo papel, o de aluno, assumindo nova postura e novas responsabilidades. A escola teve, portanto, papel primordial na construção social da infância ao representar um espaço destinado à separação do mundo dos adultos do mundo da infância, colocando-a em uma espécie de período de quarentena (Ariès, 1981). 
Com efeito, mudanças sociais geradas a partir da entrada da mulher no mercado de trabalho, bem como a crescente preocupação com relação à proteção das crianças, contribuíram para a criação de novas instâncias públicas de socialização. Tal fato pode ser observado na recente ampliação do período da jornada escolar, na criação de espaços especialmente destinados às crianças como clubes, academias, bufês, entre outros.

No entanto, a partir do momento em que um número cada vez maior de pais passa a fazer uso de tais serviços, e em muitos casos não acompanhando as experiências de seus filhos, é possível observar o discurso paradoxal que afirma que os adultos cada vez mais gostam e se preocupam com as crianças, embora dediquem cada vez menos tempo a elas.

Esse exemplo demonstra o quanto as atitudes sociais em relação à infância contradizem muitas vezes os discursos socialmente construídos. Ainda que na contemporaneidade um maior número de casais opte por ter filhos, cada vez menor é o tempo dedicado a eles, em razão das diversas demandas exigidas socialmente, "o que revela a existência de uma [...] ambivalência das atitudes sociais dos adultos perante a infância no que diz respeito à relação entre o que queremos para as nossas crianças e as condições em que algumas vivem". (Qvortrup, 1999, p .3)

Porém, ainda que um maior número de mulheres deseje ser mãe, conforme aponta Qvortrup (1999, p.3), estatisticamente, há um menor número de crianças do que há um século. Segundo os demógrafos e demais especialistas da área, há uma tendência atual de os casais optarem por um menor número de filhos que casais do século passado.

Segundo dados da Pesquisa Nacional por Amostra de Domicílios (PNAD) realizada em 2009 (IBGE, 2009), a taxa média de fecundidade vem diminuindo, logo, o grupo geracional infância possui cada vez menos membros. Esse fenômeno pode ser analisado a partir de dois pontos de vista: como consequência de transformações sociais ocorridas no contexto das sociedades modernas, dentre elas o ingresso e permanência da mulher no mercado de trabalho, seu desejo de ascensão às carreiras profissionais ligadas à ampliação do seu grau de escolaridade, redefinição das noções de maternidade e como fator impactante da construção social da infância, de maneira a transformá-la.

O fenômeno de redução do número de nascimentos pode ser concebido como uma consequência característica da vida 
moderna, conforme apontado anteriormente, e constitui um dos paradoxos do discurso atual sobre a infância, na medida em que cada vez mais setores da sociedade civil sustentam o interesse por ela, interesse esse demonstrado pela ampliação do debate e das pesquisas ao seu redor, embora esse grupo geracional tenha assistido à diminuição dos seus membros.

Com o número de seus membros reduzidos, a infância vem sendo objeto de preocupação e medo dos adultos no que se refere à sua segurança. 0 medo excessivo por parte dos adultos vem sendo denominado de síndrome do bicho-papão (Corsaro, 2011) e em parte está relacionada à sentimentalização das crianças, processo desenvolvido aos poucos durante os séculos XVIII e XIX.

0 excesso de casos de violência praticados contra crianças veiculados pela mídia tem contribuído para o fenômeno, na medida em que observamos que nos últimos anos tais casos foram objeto de extrema atenção nos noticiários. Com isso, a insegurança tomou conta dos adultos, principalmente daqueles que possuem filhos, os quais tomaram iniciativas referentes à proteção das crianças, limitando suas experiências a espaços públicos e separando-os do mundo dos adultos. Os efeitos desse mal-estar podem ser descritos pela utilização do termo domesticação das crianças.

O estatuto social da infância é configurado, conforme afirma Sarmento (2005), a partir da articulação de três Ps: Participação, Provisão e Proteção. É justamente no âmbito da proteção que está relacionada à síndrome: a excessiva preocupação com a proteção fez com que os demais Ps sofressem desinvestimento institucional. Na medida em que o foco recaiu na proteção, a participação das crianças na esfera pública foi reduzida e suas experiências limitadas aos espaços privados de socialização. Embora as crianças sejam objeto de preocupação no que se refere à segurança, esta preocupação não se estende às demais áreas na mesma intensidade, de forma que tais práticas "fazem coincidir proteção com participação - como retira às crianças o estatuto de atores sociais, destinando-Ihes a função exclusiva de destinatários das medidas protetoras dos adultos, inerentemente sábios, racionais e maduros" (Sarmento e Pinto, 1997, p. 19-20).

Embora as crianças sejam objeto de atenção e proteção, a necessidade de receber provimentos alheios tem gerado uma "estranha combinação de sentimentalismo e senso de superioridade" (Sarmento, 2007), ou seja, os adultos têm como consenso de que é necessário proteger as crianças dos males 
externos, no entanto, não levam a criança em consideração, e não compreendem que o fato de não escutá-la pode representar um dos maiores males, negando a noção da criança enquanto ator social. Isso se dá pelo fato de a infância, enquanto grupo geracional, ser concebida como um grupo invisível ou marginalizado frente os demais grupos sociais e de a imagem socialmente sustentada ser considerada sempre inferior a dos adultos.

Sarmento (2007), analisando as diversas imagens sociais da infância, concluiu que muitas delas foram construídas em torno da negatividade, recusando a concepção da criança enquanto ser social atuante, pelo fato de ela ser "considerada como o não adulto e este olhar adultocêntrico sobre a infância registra especialmente a ausência, a incompletude ou a negação das características de um ser humano completo" (p.33).

Esses seriam apenas alguns dos paradoxos contemporâneos acerca da infância, outros são sistematizados por Qvortrup (1999), revelando a contradição existente entre as representações sociais da infância e as práticas a ela destinadas:

1. Os adultos querem e gostam de crianças, mas as têm cada vez menos, enquanto a sociedade Ihes proporciona menos tempo e espaço.

2. Os adultos acreditam que é benéfico quer para as crianças, quer para os pais passarem tempo juntos, mas vivem cada vez mais vidas separadas.

3. Os adultos gostam da espontaneidade das crianças, mas estas veem as suas vidas serem cada vez mais organizadas.

4. Os adultos afirmam que as crianças deveriam estar em primeiro lugar, mas cada vez mais são tomadas decisões de nível econômico e político sem que as mesmas sejam levadas em conta.

5. A maior parte dos adultos acredita que é melhor para as crianças que os pais assumam sobre elas maior responsabilidade, mas, do ponto de vista estrutural, as condições que estes têm para assumir esse papel deterioram-se sistematicamente.

6. Os adultos concordam que se deve proporcionar o melhor início de vida possível às crianças, mas estas pertencem a um dos grupos menos privilegiados da sociedade.

7. Os adultos concordam que se deve ensinar às crianças o significado de liberdade e democracia, mas a sociedade limita-se a oferecer preparação em termos de controle, disciplina e administração.

8. Os adultos atribuem geralmente às escolas um papel importante na sociedade, mas não se reconhece como válida a contribuição das crianças na produção de conhecimentos. 
9. Em termos materiais, a infância não importa aos próprios pais, mas antes à sociedade. Contudo, a sociedade deixa os custos por conta dos pais e das crianças (p.2-3).

\section{Considerações finais}

0 presente artigo visou analisar o desenvolvimento da Sociologia da Infância a partir das rupturas conceituais com a corrente teórica conhecida como Sociologia Clássica, bem como compreender as principais ideias no campo sociológico que contribuíram para a emergência e legitimação do novo campo.

Nesse sentido, tivemos como objetivo contribuir para a difusão dos estudos estruturais que têm se desenvolvido a partir dos questionamentos acerca da influência das forças macroestruturais para o grupo geracional da infância, além de mostrar que as transformações sociais ocorridas a partir da desagregação da tradição e do costume fundaram uma nova ordem social, designada pelos sociólogos como modernidade, a qual é definida por representar um universo cultural variado e diversificado de valores.

As consequências trazidas por esse novo universo cultural foram analisadas tendo como pressuposto teórico a infância enquanto grupo geracional, ou seja, compreendendo-a como grupo presente na estrutura social. Dentre as consequências analisadas, foi possível compreender que as teorias clássicas da socialização já não são capazes de explicar os novos modelos de socialização. Além disso, observamos como a modernidade e suas condições de vida contribuíram para a emergência de um discurso paradoxal sobre a infância no que se refere às relações entre ela e os demais grupos geracionais.

No entanto, percebemos a persistência de um olhar adultocêntrico sobre a infância, concebendo a criança como o "não adulto", ou seja, tomando como referência o adulto e definindo-a a partir das características que lhe faltam.

\footnotetext{
Assim sendo, a infância não é a idade da não fala: todas as crianças, desde bebes, têm múltiplas linguagens (gestuais, corporais, plásticas e verbais) porque se expressam. A infância não é a idade da não razão: para além da racionalidade técnio-instrumental, hegemônica na sociedade industrial, outras racionalidades se constroem, designadamente nas interações de crianças com a incorporação de afetos, da fantasia e da vinculação ao real. A infância não é a idade do não trabalho: todas as crianças trabalham, nas
} 
múltiplas tarefas que preenchem seus cotidianos, na escola, no espaço doméstico e, para muitas, também nos campos, nas oficinas ou na rua. A infância não vive a idade da não infância: está aí nas múltiplas dimensões que a vida das crianças (na sua heterogeneidade) continuamente preenche (Sarmento, 2007, p. 36).

Portanto, na medida em que pretendemos explorar o desenvolvimento da Sociologia da Infância bem como compreender algumas das consequências trazidas pela modernidade, mostramos uma contraposição com o olhar adultocêntrico, intencionando repensar a infância, bem como os paradoxos entre nosso discurso e nossa prática em relação a esse grupo geracional, posto que "proclamar um novo paradigma da infância é também envolver-se na reconstrução da infância na sociedade" (James e Prout, 1990, apud Ferreira, 2002, p.4).

\section{REFERÊNCIAS}

ARIÈS, Philippe. História Social da Criança e da Família. $2^{a}$ edição. Rio de Janeiro: LTC, 1981.

BAUMANN, Zygmunt. Modernidade líquida. Rio de Janeiro: Jorge Zahar, 2001.

CORSARO, William A. A Reprodução Interpretativa no Brincar ao "Faz de Conta" das Crianças. Educação Sociedade \& Culturas, Porto, n. 17, p. 113-134, 2002.

Sociologia da Infância. Tradução: Lia Gabriele Regius Reis; revisão técnica: Maria Letícia B. P. Nascimento. Porto Alegre: Artmed, 2011.

FERNANDES, Florestan. Ensaios de sociologia geral e aplicada. São Paulo: Pioneira, 1960.

FERREIRA, Manuela. Crescer e aparecer ou...para uma sociologia da infância. In: Revista de Sociologia e Antropologia da Educação, Porto, n. 17, p. 3-12, 2002. Educação, Sociedade \& Culturas

DUBET, François. A sociologia da experiência. Lisboa, Instituto Piaget, 1996. 
A formação dos indivíduos: a desinstitucionalização.

Revista Contemporaneidade e Educação. ano 3, v.3, p. 2733, 1998.

DURKHEIM, Emile. Educação e sociologia. São Paulo:

Melhoramentos, 1978.

GIDDENS, Anthony. As consequências da modernidade. São Paulo: Editora da Universidade Estadual Paulista, 1991.

\section{4.}

Modernidade e Identidade Pessoal. Oeiras: Celta,

Mundo em descontrole: o que a globalização está fazendo de nós? Rio de Janeiro: Editora Record, 2000.

IBGE - Instituto Brasileiro de Geografia e Estatística. Pesquisa Nacional por Amostra de Domicílios 2000. Rio de Janeiro, 2009.

LAHIRE, BERNARD. Homem plural: os determinantes da ação. Petrópolis: Vozes, 2002.

MARCHI, Rita de Cássia. A Teoria Social Contemporânea e a Emergência da "Sociologia da Infância" na 2a Modernidade: alguns aspectos teórico-políticos. Revista ZEROASEIS. n. 11, jan/jun. 2005. Disponível em:

<http://ww.ced.ufsc.br/ zeroseis/sumario11.html>. Acesso em: 5 out. 2009.

PROUT, A.; JAMES, A. Constructing and Reconstructing Childhood. London: Falmer, 1990.

QVORTRUP, Jens. Nove teses sobre "infância como um fenômeno social". Eurosocial Report, n. 47, pp. 11-18, Viena, 1993. Tradução de Maria Letícia Nascimento, para utilização em disciplina do programa de pós-graduação da Faculdade de Educação da Universidade de São Paulo.

Crescer na Europa: horizontes atuais dos estudos sobre infância e a juventude. CEDIC. Centro de Documentação e Informação sobre a Criança. Universidade do Minho, 1999. Disponível em: <http://cedic.iec.uminho.pt/Textos_de_Trabalho/textos/ jensqvortrup.pdf> Acesso em: 3 jan. 2010. 
A tentação da diversidade e seus riscos. Educação e Sociedade, Campinas, v. 31, n. 113, p. 1121-1136, out.-dez. 2010 a.

. A infância enquanto categoria estrutural. Educação e Pesquisa, São Paulo, v. 36, n. 2, p. 631-343, maio/ago. 2010b.

SARMENTO, M. J; PINTO, M. (Coord.) As crianças: contextos e identidades. Braga, Portugal: Centro de Estudos da Criança, 1997.

SARMENTO, M. J. Gerações e alteridade: interrogações a partir da sociologia da infância. In: Dossiê Sociologia da Infância: Pesquisas com Crianças. Educação e Sociedade. Campinas. v. 26, n.91, p. pp. 361-378, maio-ago. 2005.

. Visibilidade social e estudo da infância. In: VASCONCELOS, V. M. R; SARMENTO, M. J. (Org.). Infância (in) visível. Araraquara: J\&M Martins, 2007.

Sociologia da Infância: correntes e confluências. In: SARMENTO, M.; GOUVEA, M. C. S. (Org.) Estudos da Infância: educação e práticas sociais. Petrópolis: Vozes, 2009.

SETTON, M. G. J. . A particularidade do processo de socialização contemporânea. Tempo Social. Revista de Sociologia da USP, São Paulo, v. 17, n. 2, p. 335-350, 2005.

SIROTA, Régine. Emergência de uma Sociologia da infância: evolução do objeto e do olhar. Cadernos de Pesquisa, São Paulo, n. 112, mar., p. 7-31, 2001.

WAUTIER, Anne Marie. Por uma Sociologia da experiência. Uma leitura contemporânea: François Dubet. Sociologias, ano 05, n. 09, p. 174-214, 2006.

Recebido em fevereiro de 2012 Aprovado em março de 2012 